\title{
Core and Networking in L2 Lexical Teaching in an Input-Poor Context
}

\author{
Masanobu Sato' ${ }^{1}$, Shigenori Tanaka² \\ ${ }^{1}$ The Graduate Program of Media and Governance, Keio University, Tokyo, Japan \\ ${ }^{2}$ The Faculty of Environment and Information Studies, Keio University, Tokyo, Japan \\ Email: stanaka@sfc.keio.ac.jp
}

Received 4 October 2014; revised 18 November 2014; accepted 5 December 2014

Copyright (C) 2014 by authors and Scientific Research Publishing Inc.

This work is licensed under the Creative Commons Attribution International License (CC BY). http://creativecommons.org/licenses/by/4.0/

(c) (i) Open Access

\begin{abstract}
This paper discusses problems in developing $L 2$ lexical competence in an input-poor environment, and suggests what we can do so as to minimize the negative effects of those problems on L2 lexical learning. As an unavoidable problem, we discussed a learner strategy unequivocally used by Japanese students when learning the meaning of a new word. To enhance L2 lexical learning, we suggested that lexical core, combined with the notion of network building, has a lot of pedagogical potential. With two cases (the preposition on, and the basic verbs of communication), we demonstrated how the core schema of a lexical item(s) becomes a common thread that weaves both intralexical and inter-lexical networks.
\end{abstract}

\section{Keywords}

L2 Lexical Competence, Search-Translation-Equivalent Strategy, Lexical Core, Network-Building, Awareness-Raising

\section{Introduction}

CLT or communicative language teaching, which highlights the engagement of L2 learners in communication, has been practiced worldwide (Littlewood, 1981; Savignon, 2000). It makes use of real-life situations that naturally necessitate communication; it lets learners engage in communication by instructing them to do so-called "task-based activities” and “content-based activities” (Richards, 2001; Ellis, 2003; Brown, 2007; Brandl, 2008). While CLT leaves room for a variety of methods and techniques (Richards \& Rodgers, 2001), the activities are characteristically interactive and heuristic, and contextually authentic, because the proponents of CLT assume that an individual learns a language interactively in communication and it is important to provide students with opportunities to use the target language for communicative purposes. 
The acquisition of task handling competence is the major objective of learning and teaching a second language. However, in L2 learning, task handling is one side of the coin, of which the other side is language resources. Without the L2 language resources (words, grammar, and formulas), there is no way of performing tasks verbally in the language. Focus on language resources turns our attention to formal instruction. In inputpoor contexts, second language learning does not take place naturally. The learner needs to be taught in order to enrich their language resources. Formal teaching implies explicit instruction.

Some argue that explicit instruction indeed enhances L2 acquisition (Alanen, 1995; Carroll \& Swain, 1993; DeKeyser, 2003; Ellis, 1993; Norris \& Ortega, 2000; Robinson, 1997), while others question the benefit of it as a contributor to the acquisition of an L2 (Rosa \& O'Neill, 1999; Sanz \& Morgan-Short, 2004). The effect of explicit instruction hinges on how instruction is given to students. Some explicit instruction will give positive effects on L2 acquisition, and others will not.

In this paper, we take it that good explicit instruction enhances "awareness-raising” (Sharwood-Smith, 1981) and "network-building" (Crossley, Salsbury, \& McNamara, 2010) on the part of language learners. Awarenessraising leads to better understanding, and network-building connects the scattered dots in a meaningful way. And in this paper, we claim that "lexical core" (or the core meaning of a word) is "a key" to both awarenessraining and network-building. Lexical core leads students to raise their awareness about the meaning of a word and to guide them in the task of network building. In this paper, we discuss why we need lexical core, and how lexical core works in lexical networking.

\section{The Problem in L2 Lexical Development}

Here we discuss major problems in the area of L2 lexical development in an input-poor environment. The following discussion assumes Japanese students learning English basic words in classroom situations.

In learning L2 lexicon, adult learners after the puberty period have a strong tendency to search the L2 translation equivalent for a target L2 word. Tanaka \& Abe (1985) called this strategy "the search translation equivalent (or STE) strategy". Given a new word in context, the teacher typically explains its meaning in L1 (i.e., Japanese). The teacher may ask students the meaning of the word, and be satisfied if the answer is given in Japanese. With the word governance and compliance, for example, the teacher explains their meanings by referring to their Japanese equivalents. In a vocabulary test, students are asked to say the meaning of governance or compliance, and expected to give their Japanese equivalents (i.e., touchi for governance, and houreijunshu for compliance). This type of instruction is called "translation-based instruction (TBI)", which motivates and reinforces the learner's use of the STE strategy.

The STE strategy may work well in the area of topic-based vocabulary development (e.g., business-related vocabulary). However, it has intrinsic problems in dealing with polysemous words, or words with multiple dictionary meanings. Given the basic verb take, for example, the teacher presents his or her students an exemplar like "John took first prize in the contest", and explains: the word take in this case means toru in Japanese. Some teachers let students infer the meaning of take contextually, but in this case, the students use the STE strategy, and formulate the "take = toru" hypothesis. The story of take does not end here, because it has greater meaning potential. When a student encounters another exemplar like "Let me take your temperature", he or she realizes that his or her initial hypothesis does not work here, and instead, the student adds another translation equivalent hakaru to his or her hypothesis. The student will encounter a number of exemplars using take, and every time he or she experiences an exemplar which cannot be assimilated into his or her pre-existing hypothesis, the student adds another $\mathrm{L} 1$ equivalents to his or her list.

The STE strategy is a transfer-based learning strategy, which requires the student to make a great deal of interlingual adjustment or "relexification" (Sprouse, 2010), in which the concepts of Japanese lexical items are replaced by the words of English. However, this strategy has intrinsic problems which challenge relexification.

First, we have a problem of "semantic discontinuity". In English exemplars, take remains take irrespective of contextual differences; the same take is used across different exemplars. By contrast, the Japanese equivalents describing the meanings of take are all different words, which are semantically totally unrelated. In the process of learning the meaning potential of take using the STE strategy, the learner has a strong impression that the meanings of take are diverse and complicated. As the degree of diversity and complexity increases, learning burden increases. Polysemy refers to the case of a word having "multiple related meanings". Semantic discontinuity breaks the semantic relatedness of those meanings, and ends up treating the meanings as if they were dis- 
tinct and unrelated.

There is another problem, which is called the problem of "semantic circularity". This problem is formulated as follows: No matter how many L1 equivalents the student adds to her or her list, the student always comes back to the original question of "what is the meaning of take?" Even if the student memorizes a complete list of dictionary meanings, the list does not successfully capture the meaning of the word, because Japanese toru, for example, corresponds not only to take, but also to other verbs such as catch, hire, pick and pass, as in the following expressions: "kawa-de sakana-o totta" ("I caught some fish in the river"), "kaisha-wa 3 nin no shainwototta” ("The company hired three persons”), "ote-nitottemitekudasai” ("Pick it up and take a look at it”) and "shio-o tottekudasai” (“Could you pass the salt?”). The same goes for other L1 equivalents for English take. If English take corresponds to $n$ L1 equivalents, then each L1 equivalent corresponds to $n$ English verbs, and this process continues endlessly, thus resulting in sematic circularity.

\subsection{A Solution: Lexical Core}

Assuming that the learner's use of the STE strategy is inevitable because learning always depends on the pre-existing knowledge, we propose that focusing on "lexical core" minimizes the problems of semantic discontinuity and circularity.

Let us suppose that the teacher wants to teach the meaning of take to Japanese students. The question here is: Does a basic verb have multiple meanings as shown in a dictionary? The teacher may assume that a verb like take is highly polysemous, having a number of multiple meanings associated with it. This view is widely accepted, and if such is the case, then there is no way of avoiding the problems of semantic discontinuity and circularity in learning L2 vocabulary. If the verb take has 20 meanings, the teacher is most likely to present only some of them (a sample) in context. For example, the student will encounter the use of take in a sentence like "Let me take your temperature" or "Let's take a picture of this statue." The student will add "take one's temperature" and "take a picture" to his list of collocations using take. However, at the same time, the student understands the meanings of the collocations on the basis of their Japanese equivalents: for example, "take one's temperature" and "take a picture" will be understood as meaning "taion o hakaru" and "shashin o toru", respectively. Here, Japanese hakaru and toru are totally different verbs, and the student naturally suffers the problem of semantic discontinuity. Yet the question is: Is it true that the verb take has a number of distinct meanings? In this regard, Vygotsky (1962) noted:

"A word acquires its sense from the context in which it appears; in different contexts, it changes its sense.

Meaning remains stable throughout the changes of sense.” (p. 146)

In a similar vein, Bolinger (1977) explains:

"Now we find a single overarching meaning which performance variables imbue with local tinges that pass for distinct senses. The deception is like what happens when we meet an acquaintance in an unexpected setting: we may not recognize him.” (p. 19)

More specifically, Miller (1978) distinguishes a core concept from contextual meanings as follows:

“...Given an occurrence of line, the problem is not to choose among fifty or more pre-stored concepts or rules but to sharpen a core concept in a manner appropriate to the discourse and the sentence in which the word occurs. In other words, perhaps line looks so polysemous because lexicographers have dragged in a lot of contextual information that is really not part of its meaning.” (p. 102)

Agreeing with Miller, Ruhl (1989) advanced "the monosemic hypothesis" when he says: common verbs such as take, give, come, go, see, break, and hit are indeed monosemic and judged polysemous by dictionaries and linguists because their essential general meanings are confused with contextual, inferential meanings.

We argue that the idea expressed here, or what we call "the lexical core hypothesis", is valid when it applies to verbal and prepositional polysemy, in that the meaning of a verb or a preposition is a function of the values of the arguments it takes. A preposition typically functions to relate two objects spatially. The phrase "an apple in the box" can be expressed as: IN (X, Y), where the value of X is "an apple", and the value of Y, "the box", and the two objects are spatially related with the preposition in [+within the bounds of space]. The phrase "an apple on the box", or ON (an apple, the box), expresses a different spatial relation between an apple and the box. A 
verb like take functions to relate two things to describe an event: "John took a picture of Mr. Fuji” is analyzed as "TAKE [+past]" (John, a picture of Mt. Fuji). In other words, a verb (or a preposition) does not have a set of determinate meanings; rather, its core meaning is semantically indeterminate, and the semantic disambiguation of the verb in an expression depends on the context in which it appears.

Let us consider the sentence "John took some pills" to illustrate what it means by "semantic indeterminacy". Given the sentence "John took some pills", it is most likely that "took" here means "swallow". However, depending on the additional contextual information, the meaning of the verb differs as in:

John took some pills and got well. ["swallow"]

and put them on the table. ["seize"]

and got arrested. ["steal"]

to Mary. ["carry"]

This shows that the meaning of take is not fixed, rather, indeterminate and subject to contextual modulation. Lexical core takes the form of a schematic representation, and we call it "core schema" (Johnson, 1987). The lexical core of take can be schematically described as in Figure 1.

The core meaning of take can be described as "a movement of OBJECT into the HAVE space (prototypically by hand)," where the HAVE space refers to one's possessional space or territory. Thus, what is constant about the expression "John took some pills" is that John moved some pills into his HAVE space (by hand)," and the specific interpretation requires further contextual information. If the information "John had a headache" is given, then it is very likely that "John took some pills" means something like "John had [swallowed] some pills".

As shown in the core schema, there are three aspects one can highlight: (1) the source (S) where OBJECT is originally located, (2) the goal (G) where OBJECT is located as the result of taking, and the means (M) by which a movement of OBJECT takes place. The act of taking is usually achieved "by hand". The point here is that a list of dictionary meanings assigned to take can be classified into the three clusters, each representing $\mathrm{S}, \mathrm{M}$, or G. If the source aspect (S) is highlighted, then we interpret the meaning of take as similar to extract, remove, and subtract. Emphasis on the most important aspect, G, leads to the interpretation of take as similar to inject, acquire, receive, accept, and understand. The means perspective (M) can be highlighted to make take synonymous with grab, seize, and grasp.

A: Focus on the Source [S]

[+basic] Johnny took a plate from the table. $\rightarrow$ [+extended] He took 7 from 17.

B: Focus on Means [M]

[+basic] He took his pen and started writing. $\rightarrow$ [+extended] The police took the man in the act.

C: Focus on the Goal [G]

[+basic] I took the message from John. $\rightarrow$ [+extended] I can't take it anymore.

Thus, core schema is not simply a static picture, or a static representation of the lexical meaning of take; rather, within one's mind, it functions in a dynamic and flexible way, which, in turn, makes it possible for an individual to produce a variety of context-sensitive senses. To explain this dynamic nature, we refer to cognitive operations such as schema-highlighting and schema-projection. As explained above, schema-highlighting is an operation of focusing on one aspect of the core schema. For example, highlighting or focusing on the source [S] aspect of taking, we have a sentence like "John took a plate from the table". The same S-focused schema can be projected onto a more abstract situation to produce a sentence like "He took 7 from 17". This is a case of schema-

\section{take}

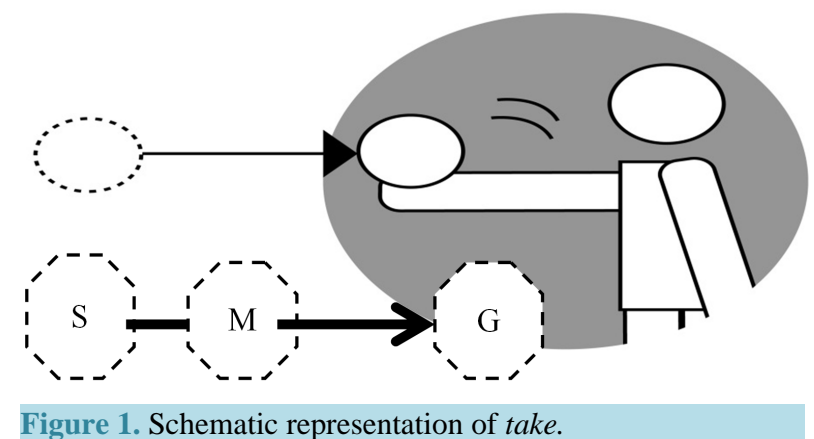


projection. Thus, the act of taking (removing) a plate from the table can be semantically connected with the act of taking (subtracting) 7 from 17.

\subsection{A Solution: Lexical Networking}

In our mind, a word or word concept does not stand alone in isolation of other words or other concepts, but rather it is linked semantically with others to produce a semantic network. Within the context of L2 acquisition, Crossley, Salsbury \& McNamara (2010) point out that "connections between words allow newly acquired words to be easily assimilated within these networks because new words are not learned in isolation, but through links to already learned words" (p. 576).

Meara (2009) states that vocabulary is a network. Using association data obtained through a word association task, he analyzed how L2 learners' lexical knowledge is connected, and how it differs from the lexical networks of native speakers, using computer-based assessment tools. We can draw one conclusion from a series of studies done by and introduced in Meara (2009) that learning isolated words is one thing, and acquiring network knowledge is another (Read, 2004). As a pedagogical implication, the teacher should help students store newly learned lexical items in a lexical network of already existing words.

The question is what form a lexical network takes specifically. There are different organizing principles of lexical networking. Words can be related in many ways. Miller \& Johnson-Laird (1976), however, note that "some efficient principles of organization exist in the lexicon in order to facilitate learning it" (p. 525). The associative principle assumes that a set of words are triggered and evoked upon hearing a given word (Meara, 2009). Those words are linked with the target word in some ways, thus forming an associative network. For example, the word drum triggers a number of words or concepts such as "instrument [superordinate concept]", "band [context]", "loud [attribute]", "trumpet [related concept]", "play the beat [action]", "Tom-Toms [part of the drum set]", and "Elvin Jones [famous drummer]", which will be clustered into an associative network. The thematic principle assumes that words are grouped by meaning referring to specific topics or fields such as cooking, stock market, nuclear energy, national election, desertification, globalization, and baseball.

We are interested in another dominant organizing principle, the conceptual principle, which assumes that words are categorized into semantic domains such as the domain of numbers and quantities, the domain of movement, the domain of utterance, and the domain of spatial relations (Miller \& Johnson-Laird, 1976). For example, the verbal domain "movement" can be expressed by different verbs such as: ascend, pivot, descend, depart, retreat, advance, progress, regress, flee, leave, sink, fall, revolve, rotate, and rise. This is not a random list, but can form a conceptual network of movement as follows:

move + [direction]

[+upward]: ascend, rise

[+around]: pivot, revolve, rotate

[+downward]: descend, fall, sink

[+away]: depart, leave, flee

[+forward]: advance, progress

[+backward]: retreat, regress

The lexical network model applies not only inter-lexically, but intra-lexically as well (Lakoff, 1987; Norvig \& Lakoff, 1987). In dealing with lexical polysemy, Lakoff (1987) represented the multiple senses of over in the form of intra-lexical network with the prototypical sense being the center of the network and other senses deriving from the prototype by means of cognitive operations such as metaphorical extension and profiling. As shown above, take is used in different situations, exhibiting different context-sensitive meanings. Those meanings are semantically related to each other and the lexical core of take explains how the different senses are related into a lexical network of word senses.

Intra-lexical networking requires a common thread, that is, lexical core, which links the different usages of a word. By contrast, inter-lexical networking requires semantic differentiation among the related words. To differentiate the meanings of semantically related words, however, we need the lexical core of each word. Lexical core has both the uniting power and the differentiating power.

\section{Lexical Core as a Guiding Principle of Lexical Networking}

In the following sections, we will look at how intra-lexical networking and inter-lexical networking are achieved 
with the common thread of lexical core: the case of on for its intra-lexical networking, the case of speak, talk, say, and tell for their inter-lexical networking.

\subsection{Intra-Lexical Network: The Preposition on}

The preposition on has different dictionary meanings associated with different situations. With the core meaning of on (i.e., [+contact]) as the common thread, the teacher asks to explore the meaning world of on. To start with, the teacher may use prototypical exemplars to introduce the usage of on. The teacher asks students to imagine the situations described by the following sentences.

1) There is a cat on the sofa.

2) Look at the fly on the ceiling.

3) The picture on the wall was painted by a famous artist.

At this point, the teacher presents the core schema of on as below, and explains that the essential meaning of on is something to do with "contact" (see Figure 2).

With the semantic feature of "contact", the teacher continues presenting examples such as the following:

4) You have mud on your shoes.

5) I saw a shadow on the wall.

6) He has a bump on the head

7) Read the label on the bottle.

At this point, the teacher demonstrates that the "contact" sense of on can be not only "surface-contact" but also "point-contact," and gives the following examples to show the point-contact (see Figure 3).

8) There's a fish on the hook.

9) There are apples on the tree.

10)My dog is on the leash.

As the extended usage of on, the teacher may introduce the different uses of on, and encourages students to think how the concept of "contact" is related to these uses.

11)Stand on one foot.

12)Can you stand on your hands for 60 seconds?

13)I usually sleep on my stomach.

At this time, students will be able to see that the core schema of on can flexibly apply to a variety of situations. The teacher will give examples of on, which require metaphorical interpretations.

14)Japanese live on rice.

15)Buy jackets on your credit card.

\section{on}

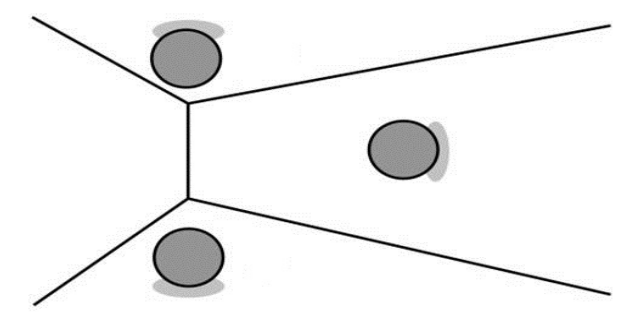

Figure 2. Schematic representation of the preposition on.
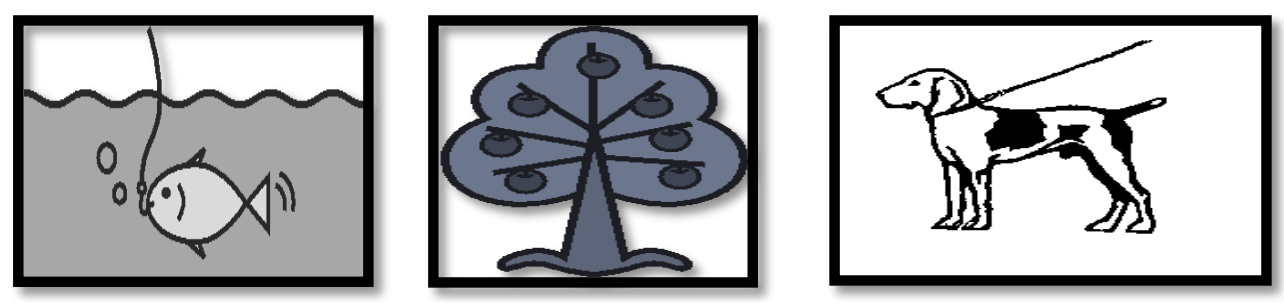

Figure 3. Exemplars of the usage of on [+point contact]. 
The "surface-contact" extends to the notion of "support". If A is on B, B supports A; if there is a book on the table, the table supports the book. Likewise, when we say, "Japanese live on rice", we imply that rice support the life of Japanese. In the same way, that your credit card supports your buying jackets is implied in "Buy jackets on your credit card." As a person is on the (moving) train, a person can be on schedule or on a diet.

The "point-contact" sense can be extended to the sense of "continuation," as in: "I’m on duty", "Be on guard", "Go on walking". The "point-contact" sense can be also extended to the sense of "fixation". For example, the song "Georgia on my mind" suggests that the protagonist always thinks of his hometown Georgia, which never leaves from his mind. Thus, "fixation" is implied here. We use the preposition on to describe a day in a calendar such as "on Monday", "on Independence Day, and "on my birthday". Here, on is used because the days of a week (e.g., Monday), national holidays (e.g., Independence Day), and one’s birthday are fixed in a calendar.

If the preposition on implies "fixation", then we can account for the difference between "a book on Indian economy" and "a book about Indian economy". The expression "a book on Indian economy" suggests that the book is fixed on the topic, without shifting from it, while the expression "a book about India economy" permits some degree of freedom in a way that the book deals with the topic.

Thus, students will be able to build an intra-lexical network of on in the following form in Figure 4.

The core meaning of on is described as [+contact], which can be either [+surface contact] or [+point contact]. This is the case of spatial contact. Metaphorically, [+surface contact] can be extended into the concept of [+support], and [+point contact] into the concept of [+continuation]. The core meaning of on can apply temporally, suggesting the sense of [+fixation on a calendar].

The extended sense of "continuation" is useful even when explaining the difference between the two constructions below:

16)On arriving at Tokyo Station, I called John at his office.

17)As soon as I arrived at Tokyo Station, I called John at his office.

The "on" construction suggests that there was no break between the two actions (i.e., I arrived at Tokyo Station and I called John at his office). In other words, the two actions are on the continuum. On the other hand, the "as soon as" construction can be used even when there was a few minutes break between the two actions. An example like "On (the count) of one, two, three, they lifted the stone" can be explained in the same way. The notion of contact can transform into "continuation" if applied to a linear sense.

\subsection{Inter-Lexical Network: Speak, Talk, Say \& Tell}

Japanese learners often get confused in their selection of a right word between speak, talk, say, and tell (Sato \& Batty, 2012). A learner who is lexically competent and functional should be able to discriminate the semantic differences of these verbs. And the point to emphasize here is that lexical choice is not simply a matter of convention, but is semantically motivated. Thus, inter-lexical competence is learnable.

The verbs speak and talk are both translated into hanasu in Japanese, which is a cause of lexical confusion among Japanese students, and the teacher needs to explain the principle of lexical choice. The teacher may start with the following examples, and ask why a gorilla cannot speak, while a parrot can.

18)A gorilla can talk, though it doesn't speak.

19)A parrot can speak, and it may talk.

A gorilla can talk to people by using sign language, not by making vocal sounds. We call such a gorilla "a talking gorilla”. If you are a user of a sign language, you can talk freely without speaking. A parrot—“a speaking parrot”- can somehow manage to imitate human sounds. For some who have a parrot in their rooms, they may feel that their parrot actually talks, responding to their questions. In that case, we will call it "a talking parrot.” The lexical cores of speak and talk are schematically and verbally described as in Figure 5.

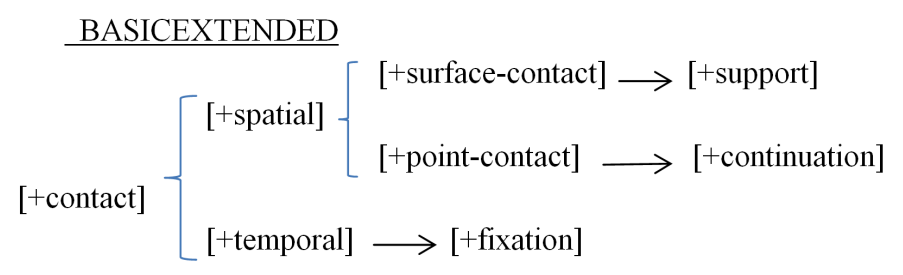

Figure 4. Intra-lexical network of the preposition on. 


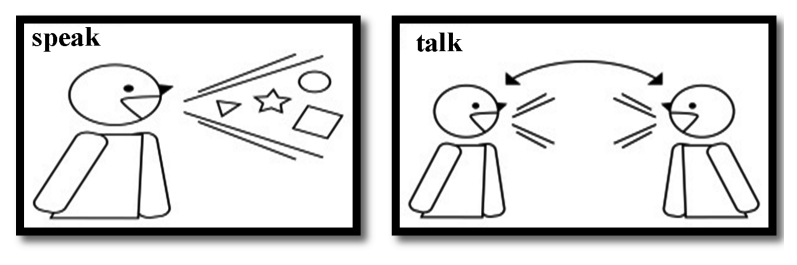

Speak: [+utterance of linguistic sound] $\rightarrow$ Focus on "one direction" Talk: [+verbal interaction] $\rightarrow$ Focus on "bi-direction"

Figure 5. Schematic representation of the verb speak.

The verb speak is used in the following examples.

20)He speaks both German and Russian.

21)Could you speak a little louder?

22)Mr. President spoke the White House press corps to the American people. He spoke forcefully and with surprising candor and empathy.

Sentence (20) is a prime example of speak [+utterance of linguistic sound]. If an illness prevents someone from making vocal intelligible sounds, we may say, for example, "He is unable to speak after a stroke”. In (22), speak [+one direction] is used because when the president of the United States makes an announcement or a speech on TV, for example, he delivers a message in one direction without expecting immediate responses from the audience. The same goes for a person who makes a speech at a formal occasion.

The feature [+utterance of linguistic sound] highlights the manner of speaking. Thus, as in (21), one can ask the partner to adjust the way of speaking. Other examples include "speak at a higher volume" and "speak at a normal volume", Likewise, in (22), modifiers like "forcefully" and "with surprising candor and empathy" refer to the manner of speaking. In other words, "speak" tends to collocate with manner adverbs: "He spoke softly", "She spoke with B.B.C. precision", "Speak out!" and the like. To add more examples, one can say, "speak in a bitter tone" and "speak in a blank voice", referring to the manner of speaking. The manner of speaking sometimes suggests a social role. Thus, we have expressions like "speak as a judge" and "speak as a public official". The feature [+utterance of linguistic sounds] can be metaphorically extended to non-linguistic sounds as in "Trumpets spoke loudly". And we have an idiomatic expression, "Actions speak louder than words".

The verb talk highlights the feature [+verbal interaction], which is well exemplified in "summit talks" and "talk shows," where the participants are actively exchanging their ideas and opinions. To explain the difference between speak and talk, the teacher may compare "We talked a lot" and "We spoke a lot". The sentence using talk implies the amount of interaction, while the expression "We spoke a lot" can be interpreted as a speakeroriented act, implying the amount of words produced by the speaker(s). The verb talk suggests the presence of, and verbal interaction with, an interlocutor. The fact that the sentence "John and Mary spoke to each other" sounds awkward suggests that in the act of speaking, interaction is not necessarily highlighted. The teacher may compare this with a natural expression, "John and Mary talked to each other."

The claim that "talking" is an interactive act is well illustrated in the sentence "Let's talk before fighting", which does not permit the substitution of speak for talk. One can "talk back", but one does not "speak back". Both imply "bi-directionality". There is a saying, "Money talks", which suggests a negotiation scene in which money plays an important role. Even the expression "He is talking to himself" assumes the interlocutor (i.e., oneself).

The preceding discussion about speak and talk has implications in terms of their semantically related clusters.

Speak-related verbs: \{express, whisper, voice, groan, scream, vocalize, utter, etc.

Talk-related verbs: \{chat, gossip, debate, discuss, consult, confer, converse, negotiate, etc.

The teacher moves on to discussing the difference between "say" and "tell", both of which are translated into $i u$ in Japanese. The verb talk does not contain [+message] as its intrinsic feature, and, hence, requires prepositions like about or of in order to indicate the topic of talking. The lexical core of the verb say is described as [+message], and that of tell, as [+message conveyance to someone] (see Figure 6).

Let us compare the two forms "saying” (noun) and "telling” (adjective). The word "saying” is something said (especially, an adage, a proverb, or an axiom), thus highlighting the message itself. The verb say has another noun form "a say", which means "an opinion”, as in "I have a say about your suggestion”. By contrast, the word "telling” is not something told; rather, "telling” means "having an effect”, or "striking” as in "a telling story”, “a 
telling argument”, and "a telling smile”, with emphasis being placed on the "conveying” part.

With the lexical core of say, we can explain why one can say, "He talked [spoke] a lot, but didn’t say much," meaning that he did a lot of talking (in a verbal interaction) or speaking, but his talking or speaking did not contain much substance. Since the lexical core of "say" is "the utterance of a message", it is the only verb that can be used to report the message spoken by someone else, as in "John said, "I like you". If someone says, "Say cheese," you are like to repeat the content "cheese". The verb say can be colloquially used as in "Whatever you say", "Enough said", and "You can say that again!"

On the other hand, "tell" has the "message-conveying" role; the verb assumes a message itself and its conveyance to someone else. Thus, "tell" is the only verb that takes the interlocutor as the object without a preposition, as in "John told me something". The remaining three verbs require the preposition to as in "say [speak, talk] to me." The verb "talk" appears in a context such as "John talked me into something". Notice, however, that the interpretation here is "John's talking caused me to be into something." In this case, "me" is not simply the receiver of what John said. The verb tell is used colloquially as: "You're telling me," meaning "You're right" and "I'm telling you," meaning "Believe me." In these usages, the message part is mutually assumed between the speaker and the interlocutor.

Thus, we have shown that the semantics of each lexical item is prerequisite to developing inter-lingual competence. When "speak" and "talk" are similar in some cases, the similarity disappears and the difference emerges with the addition of an adverb like "out." Even when "speak to" and "talk to" are used interchangeably, there are some semantic differences, which are due to the difference in lexical core meanings. To help learners develop their lexical network competence, the teacher may show how the four basic verbs of utterance function in the form of a lexical network like in Figure 7.

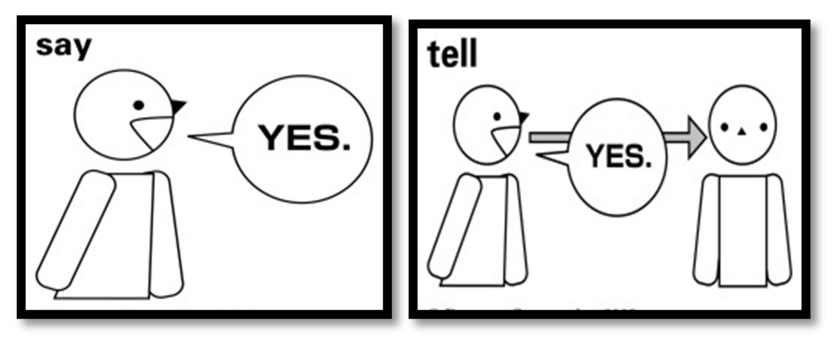

Say: [+message $] \rightarrow$ Focus on the content

Tell: $[+$ message conveyance to someone $] \rightarrow$ Focus on the content and its conveyance

Figure 6. Schematic representations of the verbs say and tell.

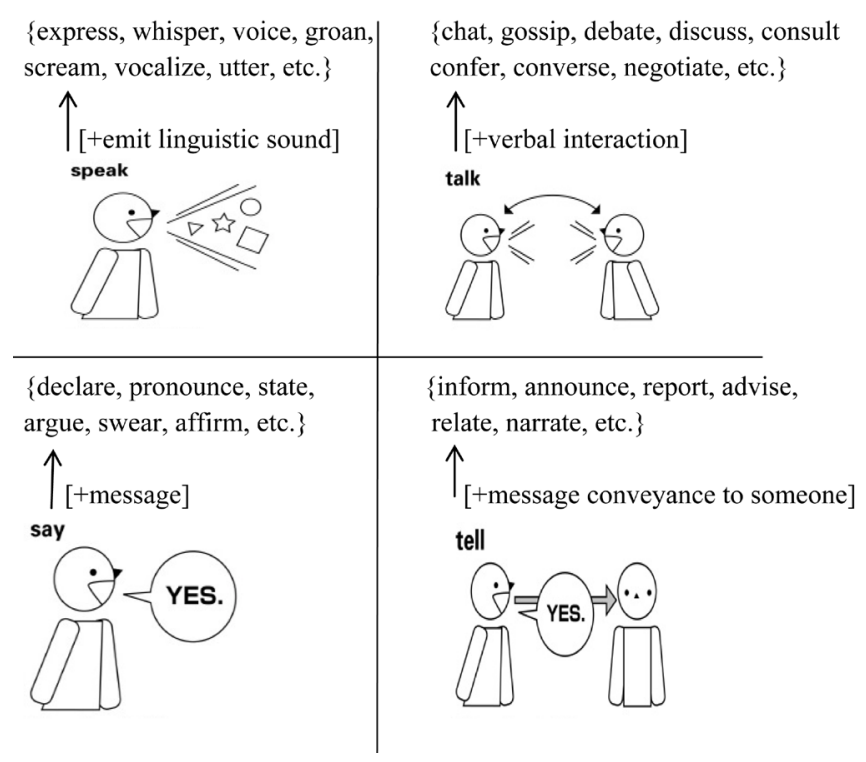

Figure 7. Inter-lexical network of basic verbs of communication. 


\section{Conclusion}

We discussed that the search-translation-equivalent strategy becomes a cause of major problems in developing L2 lexical competence in an input-poor environment. We argued that knowing the nature of the problem is a starting point of devising an effective pedagogical support. We then suggested that lexical core, combined with lexical networking, can be a powerful guiding principle in helping students develop basic lexical competence. With two case studies (the preposition on, and the basic verbs of communication), we demonstrated how the core schema of a lexical item(s) becomes a common thread, or a pedagogical device that weaves both intralexical and inter-lexical networks.

\section{References}

Alanen, R. (1995). Input Enhancement and Rule Presentation in Second Language Acquisition. In R. Schmidt (Ed.), Attention and Awareness in Foreign Language Learning (pp. 259-302). Honolulu, HI: University of Hawaii Press.

Bolinger, D. (1977). Meaning and Form. London: Longman.

Brandl, K. (2008). Communicative Language Teaching in Action: Putting Principles to Work. Englewood Cliffs, NJ: PrenticeHall.

Brown, H. (2007). Teaching by Principles: An Interactive Approach to Language Pedagogy (3rd ed.). London: Pearson Education ESL.

Carroll, S., \& Swain, M. (1993). Explicit and Implicit Negative Feedback: An Empirical Study of the Learning of Linguistic Generalization. Studies in Second Language Acquisition, 15, 357-386. http://dx.doi.org/10.1017/S0272263100012158

Crossley, S., Salsbury, T., \& McNamara, D. (2010). The Development of Polysemy and Frequency Use in English Second Language Speakers. Language Learning, 60, 573-605. http://dx.doi.org/10.1111/j.1467-9922.2010.00568.x

DeKeyser, R. (2003). Explicit and Implicit Learning. In C. Doughty, \& M. H. Long (Eds.), The Handbook of Second Language Acquisition (pp. 313-348). Oxford: Blackwell. http://dx.doi.org/10.1002/9780470756492.ch11

Ellis, N. (1993). Rule and Instances in Foreign Language Learning: Interactions of Explicit and Implicit Knowledge. European Journal of Cognitive Psychology, 5, 289-318. http://dx.doi.org/10.1080/09541449308520120

Ellis, R. (2003). Task-Based Language Learning and Teaching. Oxford: Oxford University Press.

Johnson, M. (1987). The Body in the Mind: The Bodily Basis of Meaning. Chicago, IL: University of Chicago Press.

Lakoff, G. (1987). Women, Fire and Dangerous Things: What Categories Reveal about the Mind. Chicago, IL: University of Chicago Press. http://dx.doi.org/10.7208/chicago/9780226471013.001.0001

Littlewood, W. (1981). Communicative Language Teaching: An Introduction. Cambridge: Cambridge University Press.

Meara, P. (2009). Connected Words: Word Associations and Second Language Lexical Acquisition. Amsterdam: John Benjamin. http://dx.doi.org/10.1075/lllt.24

Miller, G., \& Johnson-Laird, P. (1976). Language and Perception. Cambridge, MA: Harvard University Press. http://dx.doi.org/10.4159/harvard.9780674421288

Miller, G. (1978). Semantic Relations among Words. In H. Halle, J. Bresnan, \& G. Miller (Eds.), Linguistic Theory \& Psychological Reality (pp. 60-118). Cambridge, MA: MIT Press.

Norris, J., \& Ortega, L. (2000). Effectiveness of L2 Instruction: A Research Synthesis and Quantitative Meta-Analysis. Language Learning, 50, 417-528. http://dx.doi.org/10.1111/0023-8333.00136

Norvig, P., \& Lakoff, G. (1987). Taking: A Study in Lexical Network Theory. Proceedings of the 13th Berkeley Linguistics Society Annual Meeting, 195-206.

Read, J. (2004). Plumbing the Depths: How Should the Construct of Vocabulary Knowledge Be Defined. In P. Bogaards, \& B. Laufer (Eds.), Vocabulary in a Second Language (pp. 209-227). Amsterdam: John Benjamin. http://dx.doi.org/10.1075/lllt.10.15rea

Richards, J., \& Rodgers, T. (2001). Approaches and Methods in Language Teaching. Cambridge: Cambridge University Press.

Richards, J. C. (2001). Approaches and Methods in Language Teaching (2nd ed.). Cambridge: Cambridge University Press. http://dx.doi.org/10.1017/CBO9780511667305

Robinson, P. (1997). Generalizability and Automaticity of Second Language Learning under Implicit, Incidental, Enhanced, and Instructed Conditions. Studies in Second Language Acquisition, 19, 223-247.

Rosa, E. E., \& O’Neill, M. (1999). Explicitness, Intake, and the Issue of Awareness: Another Piece to the Puzzle. Studies in Second Language Acquisition, 21, 511-556. http://dx.doi.org/10.1017/S0272263199004015

Ruhl, C. (1989). On Monosemy: A Study in Linguistic Semantics. New York: State University of New York Press. 
Sanz, C., \& Morgan-Short, K. (2004). Positive Evidence vs. Explicit Rule Presentation and Explicit Negative Feedback: A Computer-Assisted Study. Language Learning, 54, 35-78. http://dx.doi.org/10.1111/j.1467-9922.2004.00248.x

Sato, Y., \& Batty, A. (2012). A Study of Learners' Intuitions behind the Use of Utterance Verbs in English. Vocabulary Learning and Instruction, 1, 29-36. http://dx.doi.org/10.7820/vli.v01.1.sato.batty

Savignon, S. (2000). Communicative Language Teaching. In M. Byram (Ed.), Routledge Encyclopedia of Language Teaching and Learning (pp. 125-129). London: Routledge.

Sharwood-Smith, M. (1981). Consciousness Raising and the Second-Language Learner. Applied Linguistics, 2, 159-168.

Sprouse, R. (2010). The Invisibility of SLA Theory in Mainstream Creole Linguistics. Second Language Research, 26, 261-277. http://dx.doi.org/10.1177/0267658309337758

Tanaka, S., \& Abe, H. (1985). Conditions on Interlingual Transfer. In P. Larson, E. Judd, \& D. Messerschmitt (Eds.), On TESOL '84: A Brave New World for TESOL (pp. 101-120). Washington DC: TESOL.

Vygotsky, L. (1962). Thought and Language. Cambridge, MA: MIT Press. http://dx.doi.org/10.1037/11193-000 
Scientific Research Publishing (SCIRP) is one of the largest Open Access journal publishers. It is currently publishing more than 200 open access, online, peer-reviewed journals covering a wide range of academic disciplines. SCIRP serves the worldwide academic communities and contributes to the progress and application of science with its publication.

Other selected journals from SCIRP are listed as below. Submit your manuscript to us via either submit@scirp.org or Online Submission Portal.
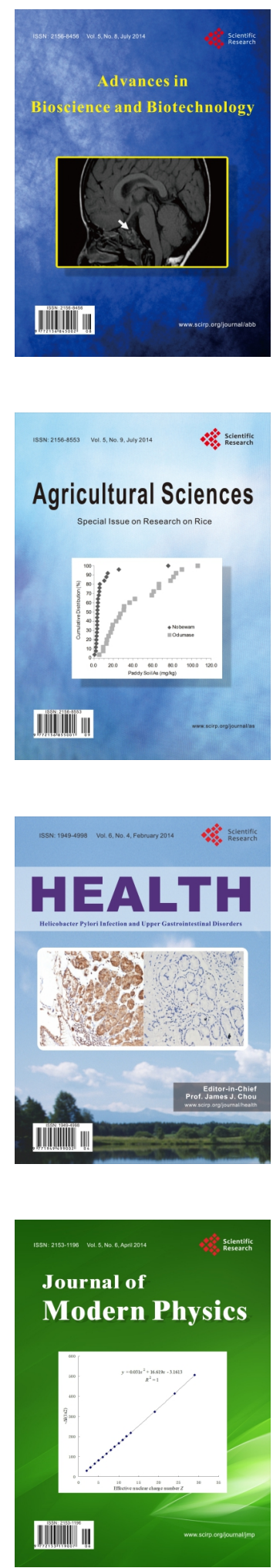
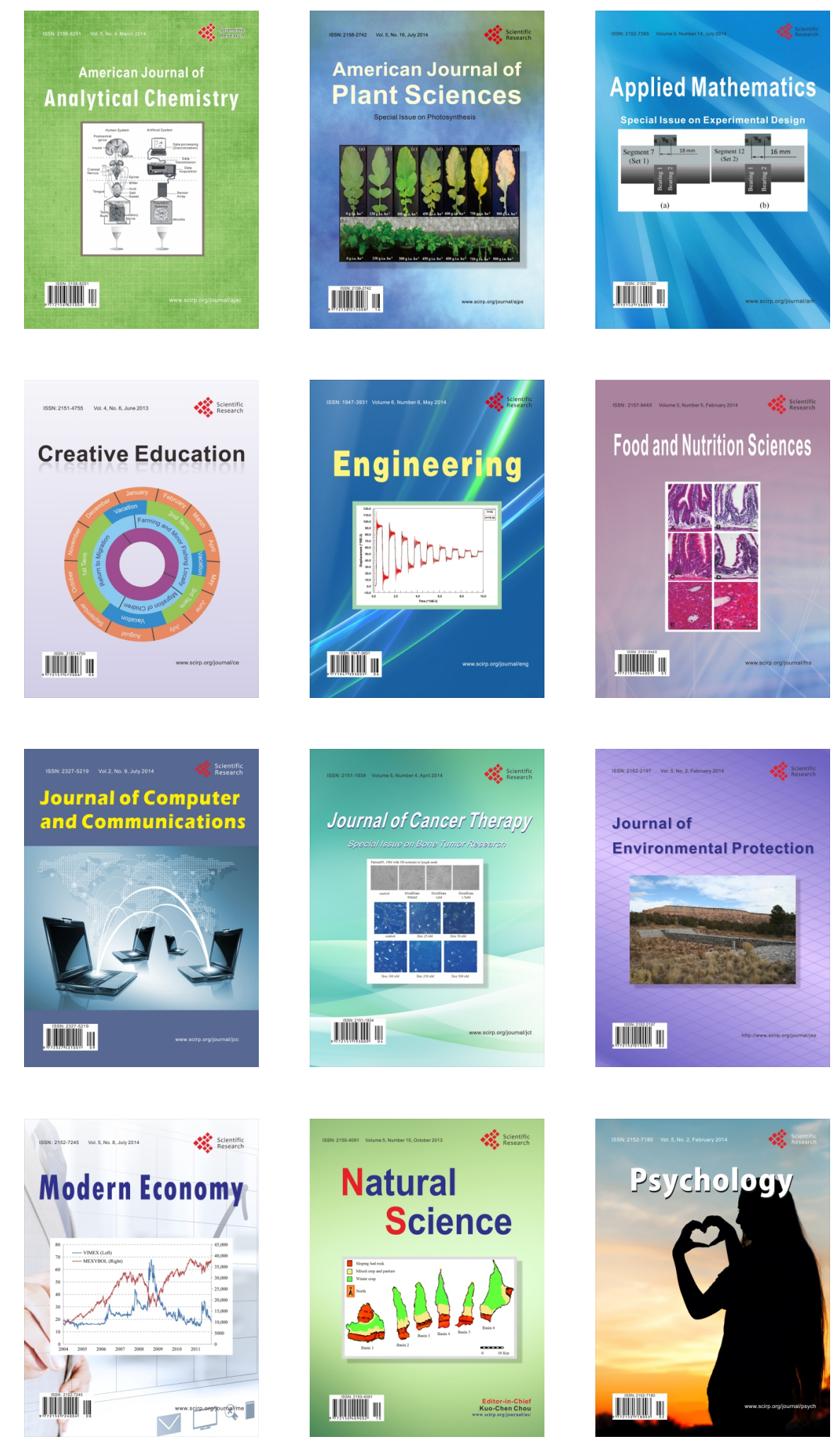